\title{
CAN CUSTOMER RELATIONSHIP MANAGEMENT CREATE CUSTOMER AGILITY AND SUPERIOR FIRMS' PERFORMANCE?
}

\author{
Vu Minh Ngo* \\ University of Economics Ho Chi Minh City \\ Hieu Minh Vu \\ Van Lang University
}

\begin{abstract}
The growing importance of Customer relationship management (CRM) and agility in any business are universally accepted and extensively investigated in different disciplines. However, lacking empirical evidence for the suggested theoretical framework of agility and their interrelationships with CRM and superior's financial performance hinders its application in the practices. Thus, this study attempted to address this issue by drawing on the Resource-Advantage theory of sustainable competitive advantages to examine a mechanism through which CRM implementation can generate sustainable competitive and achieve superior financial performance using the Vietnamese tourism industry context. The framework was tested on data collected from 231 Small and Medium Enterprises (SMEs) using Partial Least Square Structural Equation Modeling (PLS-SEM). Findings suggested that different types of CRM processes do not equally influence customer agility, and not all attributes of customer agility exert positive impacts on firms' performance as well. Also, CRM performance measurement systems were found to moderate these effects positively and substantially. Several practical implications were also derived from the research findings.
\end{abstract}

Keywords: Customer Agility, Customer Relationship Management (CRM), Firms' Performance, ResourceAdvantage Theory, Small and Medium Enterprises (SMEs), Tourism Industry.

Received: 30 April 2019

Accepted:31 December 2020

https://doi.org/10.33736/ijbs.3169.2021

\section{INTRODUCTION}

As business environments have been characterized by continually changing conditions and disruptive innovations, customers have also been more diverse in their choices and preferences. As a result, the focuses of today's firms are not only about how efficient they convert inputs into final outputs only but also and more importantly about understanding customers to know exactly what products/services to deliver effectively (Dyche, 2002). Though Customer relationship management (CRM) implementation has evolved over time and has been playing pivotal roles in business processes, solely CRM program implementation is not the guarantee for the firms' survival and prosperities in the long-term. A conventional CRM might provide a positive influence on the firm's

\footnotetext{
* Corresponding author: University of Economics Ho Chi Minh City, School of Banking. Address: 59C Nguyen Dinh Chieu Street, Ward 6, District 3, Ho Chi Minh city, Vietnam; Mobile: +84987686945; Email: vunm@ ueh.edu.vn; ORCID: https://orcid.org/00000003-1134-8072
} 
performance, if any. However, solely CRM implementation has been losing their advantages overtime when it is becoming the norms in the market. With this point of view, a remarkably successful CRM implementation should be integrated with other firms' specilized capabilities to be long-term effective (Zineldin, 2005; Alipour \& Mohammadi, 2011).

This paper attempts to fill this gap on the topic of CRM- firm's performance relationship by drawing on the Resource-Advantage (R-A) theory developed by Hunt and Morgan (1995). R-A theory has been evolved to be one of the prestigious theories on explaining the long-term firms' abnormal financial performance in many disciplines. Drawing from R-A theory and for dealing with the constantly changing business conditions, this paper employs the customer agility emerged from the manufacturing sectors (Christopher, 2000) as the mediators for CRM-superior financial performance relationship. Customer agility is integrated with CRM practices and generate the marketplace positional advantages for the firms by sensing and responding to customer demands' change sooner, astutely, and fortuitously than competitors over time (Roberts \& Grover, 2012a). Even though frameworks of agility and its attributes are extensively researched, empirical evidence tested these frameworks are minimal. Therefore, this study also attempts to somewhat bridge the gap in agility topic by providing empirical evidence on the antecedents and consequences of customer agility. In addition, this study argued that having mechanisms for creating positional advantages is not enough. The feedback loop for learning, improving and adapting continuously are immensely important regarding achieving sustainable positional competitive advantages (Garrido-Moreno \& Padilla-Meléndez, 2011). Given that, having a well-designed performance measurement system (PMS) for CRM practices can dramatically improve customer agilitysuperior financial performance (Kim \& Kim, 2009). As such, this study investigates the moderating effects of PMS in CRM practices on the relationship between customer agility and firms' financial performance.

Vietnam's tourism sector was chosen to be the research context for this study. Vietnam is the strongest growing tourism destination in Southeast Asia and one of the strongest in the world. The number of inbound travelers has tripled in the last decade and outperformed deeply other regional destinations in Asia. The Vietnamese tourism industry has expanded approximately two times faster than other destinations in the region in 2016 (26\% comparing to $16 \%$ in Indonesia, 12\% in Thailand and $13 \%$ in the Philippines). In 2018, according to the World Travel \& Tourism Council, tourism sector accounted for $9.8 \%$ of the total GDP of Vietnam (WTTC, 2018). However, the current swift growth cannot fully alleviate the wide gaps in tourism infrastructures and service quality between tourism firms in Vietnam and other major destinations in the regions such as Thailand, Malaysia, Indonesia or Singapore. As such, number of inbound arrivals to Vietnam and the number of customer retention are much lower than those in Thailand and Malaysia (one third comparing to Thailand in 2016) (WTTC, 2017).

The remainder of this paper is organized as follows. First, the next section reviews the theoretical background, key concepts for building the research model and proposing hypotheses for testing. Next, the methodology of the study is given. Then, data analyses are executed to provide empirical results. Finally, based on the empirical results, managerial discussions and conclusions are presented in the last part.

\section{LITERATURE REVIEW}




\subsection{Resource-Advantage (R-A) as a theoretical background}

The resource-advantage theory is an evolutionary, process theory of competition developed and introduced by Hunt and Morgan (1995). The RA theory has been developed in the literature of several different disciplines, including Marketing (Hunt, 2001; Hunt \& Arnett, 2004; Hunt \& Madhavaram, 2006), management (Hunt \& Lambe, 2000), economics (Hunt, 2000), supply chain management (Hunt \& Davis, 2008).

As its core, R-A theory integrates heterogeneous demand theory with a resource-based view of the firm to form the process theory of competition as presented in Figure 1. The process consists of two separate steps including (1) building core resources (e.g. VRIN resources) for competitive advantages and (2) seeking the positional advantages (e.g. leaders of cost-effectiveness or differential strategy in the industry). In addition, the feedback loops connect separated processes within the competitive advantage generation system and support the learning capability of organizations. As a result, the two priority and ongoing tasks of managers according to the R-A theory include (1) developing, manipulating or integrating internal and external resources to achieve the VRIN resources to achieve the competitive advantages and based on that (2) dynamically and continuously seek for the favor customers' preferences or market segments for positional advantages and superior performance (Wooliscroft \& Hunt, 2012).

CRM implementation has been referred to as one of the desired VRIN resources in the resourcebased view (Ernst, Hoyer, Krafft \& Krieger, 2011; Elmuti, Jia \& Gray, 2009). Although it provides a theoretical background for explaining the impacts of CRM on firms' performance, it is not sufficient for dealing with the fast-paced changing business conditions. Currently, there has been a substantially high failure rate of CRM implementation among firms, 90\% according to Edinger (2018). Thus, VRIN resources like CRM processes need to be accompanied by firms' capabilities to continuously search for the new market positions or customer segments in which firms can have competitive advantages. The R-A theory was arguably more comprehensive than the resourcebased view with regard to the process theory of competition for superior performance. In particular, customer agility was proposed as the complementary capabilities which can help CRM processes to achieve the market position advantages which are a necessary step toward superior financial performance. By developing specialized capabilities for sensing and responding to changes in customers' tastes and preferences, customer agility could be integrated with CRM processes for constantly identifying the disequilibrium in the markets and then exploiting them for the positional advantages and shared benefits of both customers and firms. 
Figure 1: The Resource - Advantage theory of competition.

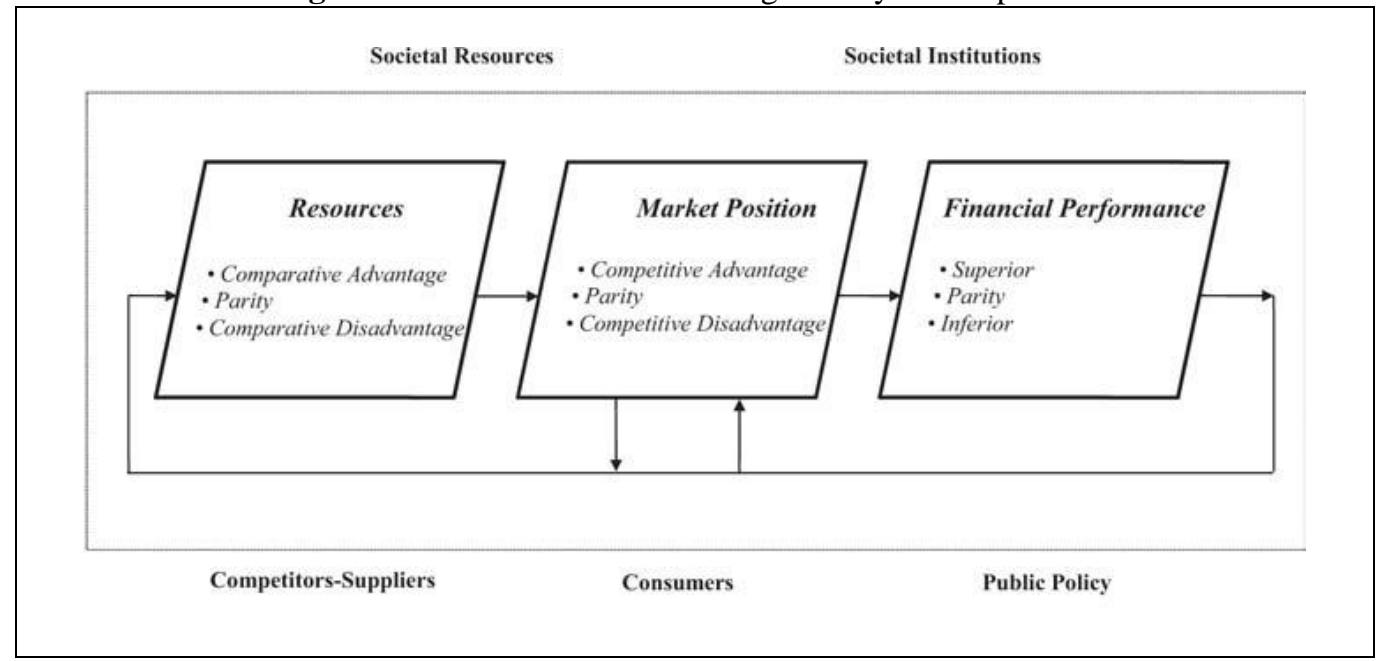

Source: Adapted from Hunt and Morgan (1997)

\subsection{Customer relationship management (CRM)}

Although definitions and benefits of CRM among researchers has been convergent over the year toward one consensus concept, the ways how to implement CRM processes has still been varied widely. It can be extracted from the literature three distinct approaches to designing CRM processes. First, some researchers define CRM processes as mainly the application of the new technology in managing customer relationships (Chang, Park \& Chaiy, 2010; Sivaraks, Krairit \& Tang, 2011). Especially, there are rising interests in the e-CRM which use the Internet as the platform for the delivery of CRM function on the web (Feinberg \& Kadam, 2002; Harrigan, Ramsey \& Ibbotson, 2011). Second, recent researches define CRM processes as the strategic management system (Payne \& Frow 2005; Ernst et al., 2011). In this approach, the main tasks are to define which is the key customer or customer segments and allocate the appropriate level of resources to these customers (Ryals, 2005). Another main area in this approach is customer information management and exploitation. Finally, the third approach emphasizes the contextdependent characteristics of any CRM implementation program (Reinartz, Krafft \& Hoyer, 2004; Kim \& Kim, 2009; Reimann, Schilke \& Thomas, 2010). This study takes the customer-facing level of CRM implementation as the approach to frame the specific CRM processes. In this level, CRM processes concentrate on the relationships between firm and customer over the customer life cycle which includes Customer initiation, Customer maintenance, and Customer termination.

\subsection{Customer relationship management and firms' performance}

While the CRM benefits appear to be obvious on customer outcomes in academic research, its impacts on financial performance have not received as much attention as they should be (Kumar, 2008). Especially, practitioners have recently voiced growing concerns on the vague result or even negative results of CRM implementation (Homburg, Grozdanovic, \& Klarmann, 2007; Minami \& Dawson, 2008; Ahearne, Rapp, Mariadoss, \& Ganesan, 2012). This paper would like to contribute to this noticeably lacking research body by investigating the real effects of CRM on the firm's 
financial performance. Recently, new stream of researches has been attempting to investigate the new intermediaries between CRM and financial performance.

Minami and Dawson (2008) proposed the model which uses the customization process as a mediator for transferring the impacts from CRM project to financial performance. The customization process is expected to bring value to the customer through the co-creation concept of CRM. The paper found that the direct relationship between CRM implementation is significant. However, a negative impact of Customization on financial performance was found. It is an exemplar in which the cost for initiating CRM-related processes can surpass its generated benefits on the firms' bottom line. Chang et al., (2010) tested the mediating effects of Marketing Capabilities in the relationship between CRM technology and organizational performance. In this model, the authors also include customer-centric organizational and customer-centric management system as the moderators for the link from CRM technology to organizational performance. Both moderators have positive impacts on CRM consequences confirming that human and organizational factors are essential for successful CRM projects. Marketing capabilities in this research were found to play a pivotal role in interpreting the technology of CRM into the outcomes of firms.

In another research, new product performance was proposed to be the mediator for the relationship between CRM and company performance by reasoning that CRM can leverage the customer data and customer knowledge to help new product development process align better with market requirements, thereby reducing new product failure rates and improving company performance (Ernst et al., 2011). New product performance has been confirmed as the link between CRM processes and firm's performances regardless of types of industry. More recently, Garrido-Moreno, Lockett \& García-Morales (2014) drew on the Resources-based theory and Knowledge-based theory to test the mediating role of Knowledge Management and Organizational Commitment in the CRM - organization performance relationship. They found that Knowledge Management and Organizational Commitment fully mediate the effects of CRM processes on firms' performance.

One of the few pieces of research using objective financial performance (Sales, Operating margin and Account receivable and Return on Assets) for testing the relationship between CRM and firm' performance is conducted by Haislip and Richardson (2017). It compared the actual differences in these merits between firms that have successful CRM and the controlled firms. It found that successful CRM implementation positively influences firms' operational capabilities such as increasing sales and decreasing account receivable which in turn increases the efficiencies of asset usage (operating margin) and profitability of firms (Return on Assets).

\subsection{Agile Firm and Customer Agility}

Agility was initially a concept that emerged from manufacturing scholars and practices (Gunasekaran, 1998; Yusuf, Sarhadi, \& Gunasekaran, 1999). Initially, it was though that manufacturing flexibility can be achieved by implementing the automation system or more innovative manufacturing system such as lean manufacturing (i.e. reducing setup times and costs). Then it is expected that the new lean manufacturing system will lead to the greater responsiveness of firms to changes in the market regarding product mix and volume (Christopher, 2000). However, it was soon realized that this route to manufacturing flexibility can lead to the paradox where a firm can be very effective in their manufacturing systems, yet inventory of finished products can 
be as high as several months of sales, but customers still must wait for an extended long time to get the exact products they want. Therefore, lean manufacturing can be the element of agility in manufacturing, but it cannot enable a firm to meet the precise need of the customer in real-time. Agility is imperative in an environment in which product differentiation is the top priority (Yusuf, et al., 1999; Swafford, Ghosh \& Murthy, 2008). With changing business environment, the actual manufacturing flexibility should be the function of rapid change capabilities to respond to the shifts in market-based threats and opportunities which emphasize the cooperation between manufacturers, supplier and customers (Sharifi \& Zhang, 1999; Dubey \& Gunasekaran, 2015).

Throughout the development of the topic, two main approaches to achieve enterprise agility have emerged (Yang \& Liu, 2012). First, a firm could enhance its agility by seeking for the successful exploration of a number of competitive strategies including cost efficiency, quality improvement, speed of adjustment and flexibility (Fliedner \& Vokurka, 1997; Yusuf, et al., 1999; Yusuf, Gunasekaran, Adeleye, \& Sivayoganathan, 2004; Tallon \& Pinsonneault, 2011; Lu \& Ramamurthy, 2011). Thus, agility in this perspective is constructed on inherited capabilities from lean and flexibility strategies to form a new firm capability to adapt to sudden changes in the business environment. The second approach considers agility as some sets of specific business processes that detect environmental changes then respond rapidly and effectively. As such, two main dimensions of enterprise agility comprise sensing capabilities and responding capabilities (Dove, 2001; Weill, Subramani, \& Broadbent, 2002). For example, Yang and Liu (2012) defined enterprise agility as the ability to sense and respond to changes in customers, competitors and suppliers' landscapes. Yang and Liu (2012) was among the few researches which includes and investigate the effects of direct business process for dealing with customer changes on firms' performance (Roberts \& Grover, 2012a, 2012b; Chatfield \& Reddick, 2018).

It is posited in this paper that CRM processes at a facing-customer level can create customer agility and create sustainable firms' competitive advantages over the competitors. More specifically, customer agility is constructed based on the second approach of the enterprise agility and consists of two dimensions which are "sensing capability" and "responding capability" (Roberts \& Grover, 2012a, 2012b). Besides, as suggested in Roberts and Grover (2012b), this study is interested in empirically investigating the interactions between the two attributes of customer agility: sensing and responding capabilities. It is argued that for positively impacting the firm's performance, the sensing capability and responding need to work together and sensing capability need to accurately and promptly provide sufficient information for effective and in-time responsiveness to customers.

\subsection{CRM Performance measurement system (CRM-PMS)}

The main objective of PMS as a whole is to support the decision-making process more informed and accurate by measuring business performance, analyzing metrics for indicating what is going right or wrong in business processes. While a great deal of studies on CRM has devoted to the topic of implementation frameworks, CRM strategies, technologies involvement or cases, there have been very little studies addressing the CRM performance measurement issue (Brewton \& Schiemann, 2003; Jain, Jain, \& Dhar, 2002; Kim, Suh, \& Hwang, 2003; Zablah, Bellenger, \& Johnston, 2004; Lindgreen, Palmer, Vanhamme, \& Wouters, 2006; Kim \& Kim, 2009). 
Among them, Jain et al. (2002) moved over the traditional quantitative measures such as sales, returns, retention rates or service times to include more behavior-related measures such as attitude to serve, quality perceptions. These behavior-related measures served as bridges to connect and explain how relationship-building efforts in CRM programs improve the organization's performance (Jain et al., 2002). In another research, Kim et al., (2003) adapted the Balanced Scorecard models to suggest the customer-centric Balanced Scorecard models for measuring the CRM efforts. According to this approach, the customer-centric BSC consisted of four perspectives which are: (1) customer knowledge processes which is used as the learning and innovation process in the traditional BSC; (2) customer interaction which is used as the business process perspective accordingly in the traditional BSC; (3) customer satisfaction as the customer perspective; and (4) customer value perspectives as the final results for the CRM program efforts (Kim et al., 2003). Kim and Kim (2009) suggested a process for designing PMS in CRM implementation which consists of (1) theoretical causal map; (2) the practical hierarchy for CRM success specific to each firm after considering the firm-unique factors; (3) the integrated framework for CRM Scorecard; (4) the final CRM Scorecard; and finally (5) weighted scores for each measure in the CRM Scorecard calculated. Table 1summarized the mentioned studies according to their covers on measurement criteria for PMS in CRM implementation.

Table 1: PMS in CRM implementation in literature. Source: own research

\begin{tabular}{|c|c|c|c|c|c|}
\hline & $\begin{array}{c}\text { Customer } \\
\text { perspective }\end{array}$ & $\begin{array}{c}\text { Causal } \\
\text { relationship }\end{array}$ & $\begin{array}{c}\text { Manifold } \\
\text { perspective }\end{array}$ & $\begin{array}{c}\text { Antecedent } \\
\text { elements }\end{array}$ & $\begin{array}{c}\text { Perceptual } \\
\text { factors }\end{array}$ \\
\hline $\begin{array}{l}\text { Brewton and } \\
\text { Schiemann (2003) }\end{array}$ & $\bullet$ & $\bullet \bullet \bullet$ & N.S & $\bullet$ & • \\
\hline Jain et al., (2002) & $\bullet \bullet \bullet$ & N.S & N.S & • & $\bullet \bullet \bullet$ \\
\hline Kim et al., (2003) & $\bullet \bullet \bullet$ & $\bullet \bullet \bullet$ & $\bullet \bullet \bullet$ & $\bullet$ & $\bullet \bullet$ \\
\hline $\begin{array}{l}\text { Lindgreen et al., } \\
\text { (2006) }\end{array}$ & N.S & N.S & $\bullet$ & $\bullet \bullet \bullet$ & $\bullet \bullet \bullet$ \\
\hline Zablah et al., (2004) & $\bullet \bullet$ & $\bullet \bullet$ & $\bullet$ & $\bullet \bullet$ & $\bullet \bullet \bullet$ \\
\hline Kim and Kim (2009) & $\bullet \bullet \bullet$ & $\bullet \bullet \bullet$ & $\bullet \bullet \bullet$ & $\bullet \bullet \bullet$ & $\bullet \bullet \bullet$ \\
\hline
\end{tabular}

From the analyses above, the research model and hypotheses for testing are proposed as presented as follows:

H1a: Customer sensing capabilities mediate the effects of CRM Initiation activities on superior financial performance.

H1b: Customer sensing capabilities mediate the effects of CRM Maintenance activities on superior financial performance.

$H_{1 c}$ : Customer sensing capabilities mediate the effects of CRM Termination activities on superior financial performance.

$\mathbf{H}_{2 \mathbf{a}}$ : Customer responding capabilities mediate the effects of CRM Initiation activities on superior financial performance.

$\mathbf{H}_{2 \mathrm{~b}}$ : Customer responding capabilities mediate the effects of CRM Maintenance activities on superior financial performance. 
$\mathbf{H}_{2 \mathbf{c}}$ : Customer responding capabilities mediate the effects of CRM Termination activities on superior financial performance.

H3: Customer responding capabilities mediate the effects of Customer sensing capabilities on superior financial performance.

$\mathbf{H}_{4 \mathrm{a}}$ : CRM Performance measurement system moderates the effects of Customer sensing capabilities on superior financial performance.

$\mathbf{H}_{\mathbf{4} \mathrm{b}}$ : CRM Performance measurement system moderates the effects of Customer responding capabilities on superior financial performance.

Figure 2: Research model for CRM and customer agility implementation framework.

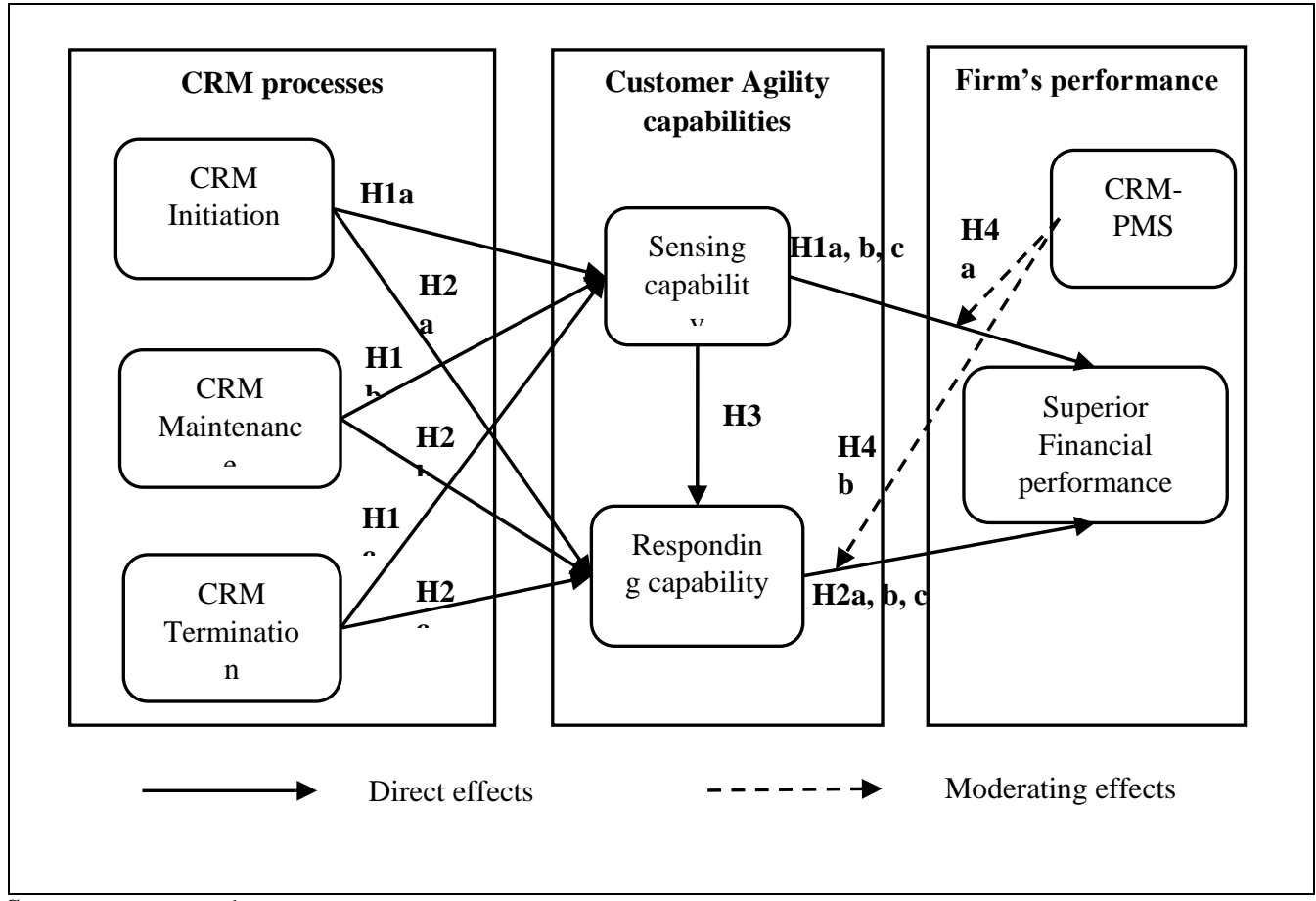

Source: own research

\section{METHODOLOGY}

\subsection{Measures}

CRM processes, Dynamic capabilities, and firm's superior financial performance phenomena in the study were treated as the latent variables and indirectly measured through observable items. A multi-item measure for three CRM processes at the customer-facing level was developed by adopting items from Reinartz et al., (2004). CRM Initiation process measures the effectiveness in identifying and evaluating potential customers, thereby differentiating communications and value propositions to targeted customers. CRM Maintenance process measures the effectiveness of 
tracking the customers' lifetime value to firms and collecting customers' data in order to adjust offers to customers. CRM Termination process measures the effectiveness in identifying unprofitable customers and actions to end the relationship with them.

A multi-item measure for two customer agility attributes was developed by adopting items from Roberts and Grover (2012b). Customer-sensing capabilities were measured via six items gauging the abilities of firms to anticipate customers' needs even before they were aware of them. Customer-responding capabilities were measured the degree at which firms react to customer changes, new customer needs and modifies their products/services for specific customer demand. CRM-PMS was measured by five items questioning the extent to which a firm satisfies five criteria about CRM performance measurement systems including: the customer perspective, causal relationship, manifold perspective, antecedent elements, and perceptual factors adopted from Kim and Kim (2009). Finally, four items were used to measure the superior financial performances comparing with key competitors as well including the overall performance, attaining market share, revenue growth, and current profitability. The reflective measurement model was used in this study because the items were assumed to be the manifestations of their underlying latent variables (Bagozzi \& Baumgartner, 1994).

\subsection{Sampling}

Based on the measures developed for capturing the study's phenomena, a survey was developed and administered to managers in small and medium enterprises (SMEs) in the Vietnamese tourism industry. Respondents give their assessments for each statement through a 7-point Liker scale with "1" to indicate "strongly disagree" to "7" to indicate "strongly agree".

The sample of SMEs in the Vietnamese tourism industry was drawn from the database of tourism firms registered at the Department of Taxation in the number of popular tourist destinations in the South of Vietnam. The first phase of the survey was conducted from June to September 2017, and the second phase was conducted from December 2017 to February 2018. Wherever possible, we followed up with phone calls to increase the response rate. The reminder emails were also sent four weeks after the initial mailing. Out of the database of approximately 1600 tourism SMEs in the South of Vietnam, a total of 238 firms participated in the survey. Out of those questionnaires received, there were seven questionnaires with missing data and thus eliminated. As a result, there were 231 questionnaires were usable which results in a response rate of $14 \%$. The respondents from SMEs consist of sales and marketing managers $(35 \%)$, general manager $(33 \%)$, front office managers $(8 \%)$ and senior sales executives (7\%). There were only eight medium firms (7\%) in the sample which have a manager who was responsible for their CRM program separately. A profile of the sample shows a reasonable spread in term of the size of the firms which participated in the survey. There were 121 firms (52\%) which have from 50 to 200 employees which were classified as medium-size firms. There were 80 firms (35\%) small-size firms that have from 10 to 50 employees and 30 micro-size firms (13\%) which have less than ten employees in the sample. The medium-sized firms in our sample serve approximately 25000 customers per year on averages and earn average revenue of about 26 billion Vietnamese Dong (about 1.2 million USD). The according numbers for small-sized firms in our sample were about 7000 customers and 7 billion Vietnamese Dong in revenue (about 0.3 million USD) 


\section{RESULTS AND DISCUSSION}

\subsection{Common method bias}

One potential problem with all self-reported data collection techniques was that they can contain the common method biases which might result from the sources such as the instrument itself or social desirability (Podsakoff, MacKenzie, Lee, \& Podsakoff, 2003). For assessing the level of common method bias in this study, we follow procedures from Podsakoff et al., (2003). The results suggest that the average variance explained by the substantive constructs of the indicator was 0.83 , while the average variance explained by the common method factor was 0.02 . The ratio was about 41.5:1. Furthermore, most of the common method factor loadings were not significant. Given the small magnitude and insignificant variance explained by the common method factor, the common method bias was unlikely to be the major concern for this study.

\subsection{Measurement model}

Table 2 presents the results of Confirmatory Factor Analysis (CFA) for evaluating the reliability and validity of the measurement model. All the six construct's Composite Reliability coefficients were larger than .70 and all the Average Variance Extracted measures (AVE) were also above .05 as presented in Table 2. These results indicate that the measurement items were reliable and the latent constructs account for more than $50 \%$ of the variances of the indicators. The Convergent Validity defining the level of agreement between the items intended to measure an underlying construct. The results show that the average loading for each block of items was rather high (from 0.8 to 0.9 ) and the range in which the loadings in each block vary was narrow (see Figure 3 ). Furthermore, the t-values indicate that all the loadings of the items on their underlying constructs were significant. These results suggest that all the items in each block help in estimating the underlying construct.

For assessing the Discriminant Validity, we follow the criterion of Fornell and Larcker (1981) which stated that if the square root of the AVE was larger than the correlation between constructs, the discriminant validity can be achieved. The results in Table 2 show that this criterion was satisfied by all the constructs which demonstrate the discriminant validity for our model.

Table 2: Correlations among latent constructs and its squared AVE, Composite Reliability coefficients, and Fit indices. Source: own research.

\begin{tabular}{ccccccccc}
\hline \hline Constructs & Composite Reliability & $F P$ & INI & MAIN & PMS & RESP & SENS & TER \\
\hline$F P$ & 0.965 & $\mathbf{0 . 9 3 5}$ & & & & & & \\
$I N I$ & 0.973 & 0.877 & $\mathbf{0 . 9 0 5}$ & & & & & \\
MAIN & 0.974 & 0.835 & 0.887 & $\mathbf{0 . 9 0 8}$ & & & & \\
PMS & 0.936 & 0.367 & 0.380 & 0.577 & $\mathbf{0 . 8 6 4}$ & & & \\
RESP & 0.972 & 0.905 & 0.899 & 0.835 & 0.476 & $\mathbf{0 . 9 2 3}$ & & \\
SENS & 0.975 & 0.850 & 0.819 & 0.843 & 0.479 & 0.920 & $\mathbf{0 . 9 3 1}$ & \\
TER & 0.916 & 0.759 & 0.764 & 0.859 & 0.606 & 0.845 & 0.882 & $\mathbf{0 . 8 8 6}$ \\
\hline
\end{tabular}

Fit Indices: SRMR $=0.028 ; \mathrm{NFI}=0.846 ;$ Chi-square $=1102.17$ 
Note: FP: Superior Financial Performance, INI: CRM Initiation, MAIN: CRM Maintenance, TER: CRM Termination; SENS: Customer sensing capabilities; RESP: Customer responding capabilities; PSM: CRM Performance measurement system. Squared AVEs were in bold.

\subsection{Hypotheses testing}

\section{The mediating effects of Customer agility capabilities}

For testing the mediating effects of Customer Sensing capabilities (SENS) (H1a, b, c) and Customer Responding capabilities (RESP) (H2a, b, c), the relationship from CRM activities to Customer agility capabilities and the relationship from Customer agility capabilities to Financial performance (FP) need to be significant. In addition, for assessing the magnitudes of any causal relationships between factors, the approach of Chen, Cohen and Chen (2010) was adopted. The fsquare metric can be calculated for measuring the effect size of an independent variable on a dependent variable as presented in Table 3 . If the f-square $\leqslant 0.02$, the effect size is too small and not substantial indicating that adding the variables as dependent variables just increases the explained variances of dependent variables less than $2 \%$. If the $0.02<\mathrm{f}$-square $\leqslant 0.15$, the effect size is small. If the $0.15<\mathrm{f}$-square $\leqslant 0.35$, the effect size is medium. If the f-square $>0.35$, the effect size is large.

Figure 3: Research model of CRM processes, customer agility, PMS, and superior financial performance

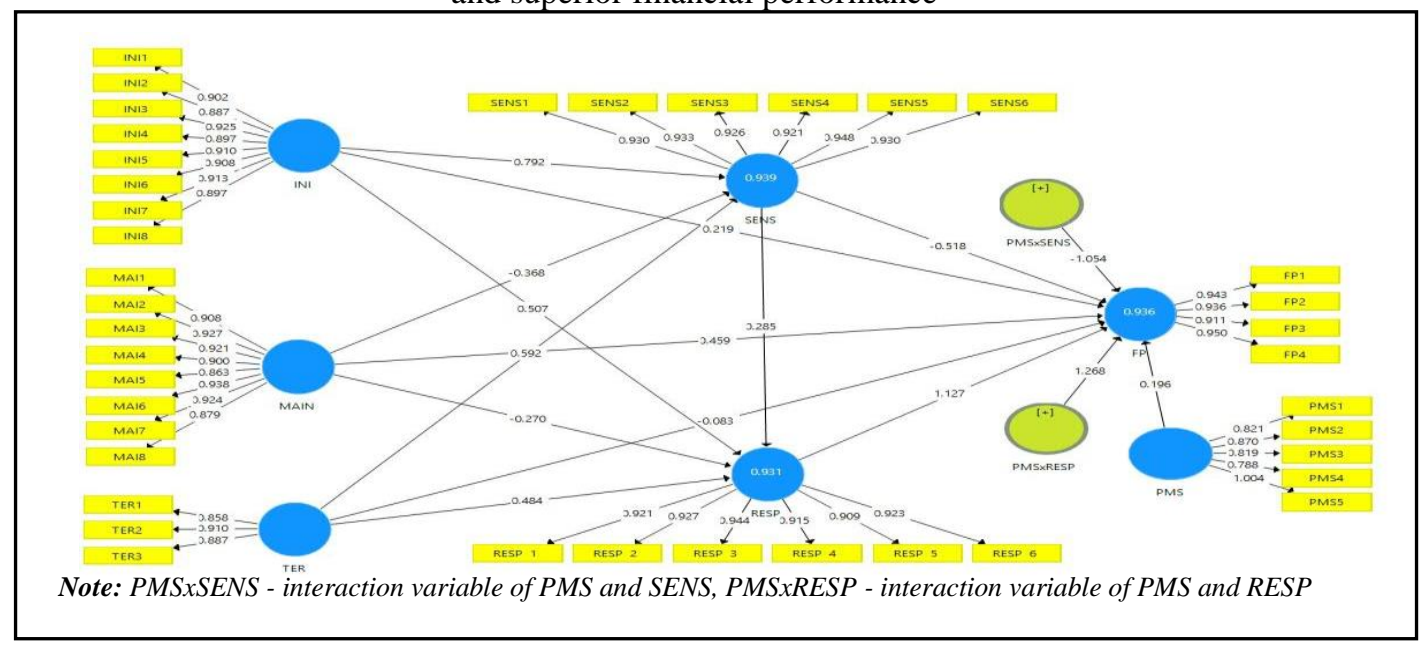

Source: own research

The results of direct path coefficients were presented in Table 3 . According to the results, the direct effects of SENS on FP was not significant $\left(\beta_{\mathrm{FP}}=-0.062\right.$, $\left.\mathrm{p}>0.05\right)$. Thus, H1a, H1b, and H1c proposing that SENSE was the mediating role in the relationship between CRM activities and FP were not supported. In addition, not all CRM activities at the customer-facing level have a significant influence on Customer Agility. Specifically, the effects of CRM Maintenances activities (MAIN) on SENSE and RESP were not significant $\left(\beta_{\text {SENS }}=-0.073, \beta_{\text {RESP }}=-0.140, p>0.05\right)$. Thus, the hypothesis $\mathrm{H} 2 \mathrm{~b}$ proposing that RESP can be the mediator for the relationship between MAIN 
and FP were not supported. Instead, MAIN have the direct, significant influence $\left(\beta_{\mathrm{FP}}=0.356, \mathrm{p}<\right.$ $0.05)$ and medium effect size (f-square $=0.296)$ on FP.

On the other hand, CRM Initiation activities (INI) $\left(\beta_{\mathrm{RESP}}=0.699, \mathrm{p}<0.05\right)$ and CRM Termination activities (TER) statistically have positive significant impacts on Customer responding capabilities $\left(\right.$ RESP) $\left(\beta_{\text {RESP }}=0.442, \mathrm{p}<0.05\right)$. Furthermore, the direct effects of RESP on FP were also positive and significant $\left(\beta_{\mathrm{FP}}=0.714, \mathrm{p}<0.05\right)$. Thus, the hypotheses $\mathrm{H} 2 \mathrm{a}$ and $\mathrm{H} 2 \mathrm{c}$ proposing that RESP can be the mediator for the relationship INI - FP and TER - FP were supported. These findings were also supported by the results of the indirect effects presented in Table 4. Especially, the direct effects of INI $\left(\beta_{\mathrm{FP}}=0.126, \mathrm{p}>0.05\right)$ and TER $\left(\beta_{\mathrm{FP}}=-0.158, \mathrm{p}>0.05\right)$ on FP were insignificant. Therefore, it can be argued that RESP fully mediated the effects of INI and TER on FP.

Table 3: Direct Path coefficients estimated from bootstrapping analysis. Source: own research.

\begin{tabular}{|c|c|c|c|c|c|}
\hline Direct Paths & Sample Mean & $\begin{array}{l}\text { Standard } \\
\text { Deviation }\end{array}$ & T Statistics & $P$ Values & $f$-square \\
\hline$I N I->R E S P$ & 0.319 & 0.073 & 4.332 & $0.000 * * *$ & \\
\hline$I N I->S E N S$ & 0.699 & 0.072 & 9.551 & $0.000 * * *$ & \\
\hline$M A I N$-> RESP & -0.073 & 0.073 & 0.991 & 0.322 & \\
\hline$M A I N->S E N S$ & -0.14 & 0.091 & 1.488 & 0.137 & \\
\hline$T E R->R E S P$ & 0.28 & 0.076 & 3.742 & $0.000 * * *$ & \\
\hline$T E R$-> SENS & 0.442 & 0.058 & 7.698 & $0.000 * * *$ & \\
\hline SENS -> RESP & 0.465 & 0.086 & 5.343 & $0.000 * * *$ & \\
\hline$I N I->F P$ & 0.126 & 0.11 & 1.07 & 0.285 & 0.025 \\
\hline$M A I N->F P$ & 0.356 & 0.106 & 3.393 & $0.001 * * *$ & 0.296 \\
\hline$T E R->F P$ & -0.158 & 0.095 & 1.652 & 0.099 & 0.179 \\
\hline$R E S P$ - > FP & 0.714 & 0.109 & 6.514 & $0.000 * * *$ & 1.160 \\
\hline$S E N S$ - > FP & -0.062 & 0.145 & 0.386 & 0.700 & 0.280 \\
\hline$P M S->F P$ & 0.099 & 0.05 & 2.053 & $0.040 * * *$ & 0.074 \\
\hline SENS $x P M S->F P$ & 0.199 & 0.043 & 4.580 & $0.000 * * *$ & 0.449 \\
\hline$R E S P \times P M S->F P$ & 0.208 & 0.045 & 4.607 & $0.000 * * *$ & 0.555 \\
\hline
\end{tabular}

Note: $* * *:$ significant at $\mathrm{p}<0.05$

Finally, we would like to test the mediating effects of RESP in the relationship between SENSE and FP. As mentioned above, the direct effect of RESP on FP was significant. Furthermore, the direct effect of SENSE on RESP was also significant $(\beta=0.465, \mathrm{p}<0.05)$ as presented in Table 3 . Thus, the mediating effects of RESP on the relationship between SENS and FP were statistically significant. As presented in Table 4, the estimated coefficients for the indirect path of SENS -> RESP $\rightarrow$ FP was positive $(\beta=0.332, \mathrm{p}<0.05)$. As a result, hypothesis $\mathrm{H} 3$ was supported.

Table 4: Indirect path coefficients estimated from bootstrapping analysis.

\begin{tabular}{|c|c|c|c|c|c|}
\hline Indirect paths & $\begin{array}{c}\text { Sample } \\
\text { Mean }\end{array}$ & $\begin{array}{l}\text { Standard } \\
\text { Deviation }\end{array}$ & T Statistics & $P$ Values & Hypotheses testing \\
\hline$I N I$-> SENS -> FP & -0.045 & 0.103 & 0.374 & 0.708 & H1a not supported \\
\hline$M A I N->S E N S->F P$ & 0.01 & 0.025 & 0.303 & 0.762 & H1b not supported \\
\hline$T E R$-> SENS -> FP & -0.029 & 0.065 & 0.38 & 0.704 & H1c not supported \\
\hline$I N I->R E S P$ - > FP & 0.228 & 0.063 & 3.585 & $0.000 * * *$ & H2a supported \\
\hline$M A I N$-> RESP -> FP & -0.051 & 0.053 & 0.972 & 0.331 & H2b not supported \\
\hline
\end{tabular}




\begin{tabular}{cccccc}
\hline \hline TER $->R E S P$ - > FP & 0.199 & 0.061 & 3.329 & $0.001 * * *$ & H2c supported \\
$S E N S$-> RESP -> FP & 0.332 & 0.081 & 4.076 & $0.000 * * *$ & H3 supported \\
\hline
\end{tabular}

Note: $* * *$ : significant at p-value $<0.05$

Source: own research.

The moderating effects of Performance measurement system (PMS)

For testing the moderating effects of PMS on the SENS-FP relationship and RESP-FP relationship, first, the scores of these constructs were mean-centered, and the products of PMS with SENSE (PMSxSENS) and RESP (PMSxRESP) were calculated to generate the interactive variables for testing the moderating effects of PMS. Then, the variables of PMSxSENSE and PMSxRESP were used to capture and control the effects of the interaction between PMS and the two Customer agility capabilities on FP in the regression analysis, which is usually called Moderated Regression analysis (MRA) (Aiken \& West, 1991).

As indicated in Table 3, the direct effects of the two interaction variables of PMS $x$ SENSE $\left(\beta_{\mathrm{FP}}=\right.$ $0.199, \mathrm{p}<0.05$ and PMSxRESP $\left(\beta_{\mathrm{FP}}=0.208, \mathrm{p}<0.05\right)$ were positive and statistically significant. Thereby, it can be concluded that PMS exerts positive moderating effects on both SENS-FP and RESP-FP relationships. Hypotheses $4 \mathrm{a}$ and $4 \mathrm{~b}$ were supported. Especially, the f-square metrics presented in Table 3 showed that the effect size of the two interaction variables of PMSxSENSE (f-square $=0.499>0.35)$ and PMSxRESP $(\mathrm{f}$-square $=0.555>0.35)$ on FP were very strong.

Figure 4: Simple slop analysis of the moderating effects of PMS on Customer agility and firm's superior financial performance relationships.

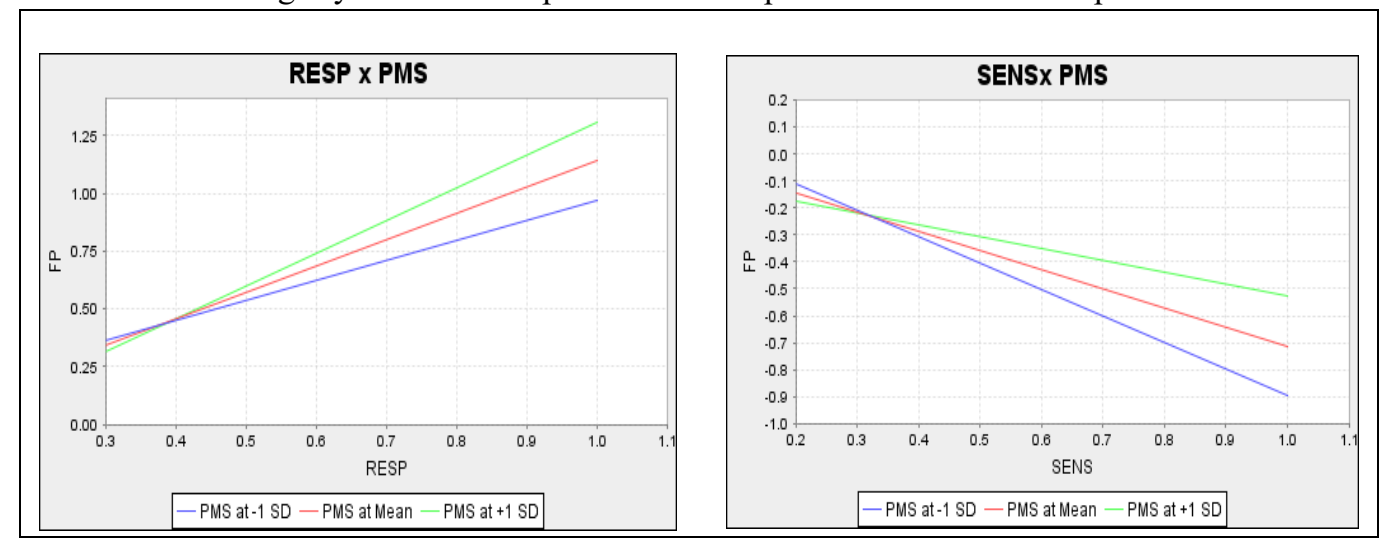

Figure 4 presented the total effects of RESP and SENS on FP at three different levels of PMS (high level of PMS $=$ mean $+1 * \mathrm{SD}$, low level of PMS $=$ mean $-1 * \mathrm{SD}$, and neutral level of $\mathrm{PMS}=$ mean). The different levels of slopes associated with different levels of PMS show the moderated effects of PMS on the relationship between the two Customer agility capabilities and FP. Specifically, Figure 4 showed that with the higher PMS level, RESP and SENS exerted stronger effects (the slope is steepest with the high level of PMS and most gradual with the low level of PMS) on FP 
than with the lower PMS level. It means that for RESP- FP and SENS-FP relationships, the better the PMS is, the higher the effects of RESP and SENSE on FP are.

\subsection{Discussion}

This study drew on the R-A theory to investigate the mechanism through which CRM implementation can generate the marketplace positional advantages, which, in turn, devote to the sustainable superior financial performance in tourism-industry context. More specifically, this study employs customer agility as the missing link between CRM processes and superior financial performance by reasoning that customer agility can provide firms with the competences to move quickly, astutely, fortuitously, and sooner than its key competitors when rapid changes happen in customer demands or tastes. In other words, customer agility capabilities using together with core resources make sure that the firm is always ahead of its competitors in identifying short-term disequilibrium in the customers' demand for exploiting the abnormal financial rewards. Keeping doing it over time is one of the possible strategies for achieving positional advantages and sustainable competitive advantages and superior financial performances for shareholders suggested by R-A theory (Hunt, 2012; Feiler \& Teece, 2014).

Interestingly, this study found that not all types of customer agility capabilities express itself as the link between CRM implementation and superior financial performance. Only specific combinations between CRM activities (Initiation and Termination) and customer responding capabilities (RESP) are successfully generated abnormal economic rewards for the firm. This finding extended literature on customer agility. This paper also extended the literature of agility by studying the interaction between two capabilities of customer agility which are Customer sensing and Customer responding capabilities suggested by Roberts and Grover (2012b). It is found that Customer sensing capabilities cannot exert direct influences on firms' financial performance and must transfer their effects via Customer responding capabilities. As such, these findings provided an unusual case for further scholar works, since previous studies are not keen on the interactions between attributes of customer agility and its effects on firms' performance. It seemed that in the tourism industry, catching up with customer changes might not yield positive results until managers use these learnings effectively for providing the customer with new value propositions and offers.

Finally, this study supplied the empirical findings that CRM performance measurement system (PMS) moderates the effects of customer agility on firms' superior financial performance. As such, PMS was found by previous studies to positively associated with firms' performance and play a role of mediating variable in many contexts (Brewton \& Schiemann, 2003; Kim \& Kim, 2009; Lisi, 2015; Micheli \& Mura, 2017). The findings suggested that developing an appropriate PMS can boost the effectiveness of how firms sensing and responding to changes in customers' preferences. This finding was consistent with recent studies on PMS claiming that a well-designed PMS was not only used by top managers but also can enable employees' to confirm or form a mental model for performing and improving their jobs simultaneously, thereby, positively influence firms' performance (Wouters \& Wilderom, 2008; Jordan \& Messner, 2012; Englund \& Gerdin, 2015). 
Therefore, managers who are looking for a nuance which can really help firms to break through the conventional customer performances can find it somehow in the moderating effects of CRMPMS.

This study also provided practical implications for managers who are seeking successful CRM implementation. First of all, the study proposed a novel comprehensive framework for successfully implementing a CRM program in the tourism sector in Vietnam. It implied that the traditional approach for CRM implementation in tourism firms is not sufficient and managers should employ the new approach as soon as possible. Second, managers in the tourism industry should consider developing customer agility capabilities for continually moving from one short-term advantage to another when necessary as a way for sustainable competitive advantages in the long-term. In the tourism sector context featuring constantly changing customers' taste and intensive competitions, this approach might help managers to build situation-specific solutions quickly and continuously evolve toward their long-term objectives. Third, it was found that only when firms employ solid actions to respond to customers' changes, the effects of CRM activities on firms' financial performances were assured.

\section{CONCLUSION}

This study draws on the R-A theory of competitive advantages for empirically testing the model of interrelationships between CRM, customer agility and firms' superior financial performance. We find that CRM initiation and CRM termination activities can facilitate a firm's ability to sense and respond to changes in customers' demands and needs. CRM maintenances activities, on the other hand, do not directly associate with firms' customer agility. Findings also suggest the mechanism through which sensing capabilities transmit its effects on firms' performance by using information and knowledge collecting from the sensing processes as inputs for responding processes to changing value propositions offered to customers. Moreover, these effects of customer agility on firms' performance will be substantially stronger when competent PMS plays the role of a moderator.

This study has some limitations, which are promising avenues for improving and developing in future research. First, it is encouraged to include in the research model the contextual factors such as environmental dynamism and turbulence to investigate the agility-firms' performance relationship in different contexts and environments. Second, it seems that not all agility attributes directly influence the firm's outcomes. Thus, it is imperative to look for possible mechanisms through which agility can exert their effects on firms' competitive advantages and performances. Finally, the constructs used for measuring agility in this study have not been generalized. Thus, it is required to develop more generalizable measures for customer agility so that researches on the agility topic are more comparable.

\section{ACKNOWLEDGEMENT}

This research is funded by University of Economics Ho Chi Minh City, Vietnam 


\section{REFERENCES}

Ahearne, M., Rapp, A., Mariadoss, B. J., \& Ganesan, S. (2012). Challenges of CRM implementation in business-to-business markets: A contingency perspective. Journal of Personal Selling \& Sales Management, 32(1), 117-129.

Aiken, L. S., \& West, S. G. (1991). Multiple regression: Testing and interpreting interactions. Newbury Park: Sage Publications

Alipour, M., \& Hallaj Mohammadi, M. (2011). The effect of Customer Relationship Management (CRM) on achieving competitive advantage of manufacturing tractor. Global Journal of Management and Business Research, 11(5), 27-35.

Bagozzi, R. P., \& Baumgartner, H. (1994). The evaluation of structural equation models and hypothesis testing. Principles of marketing research, 1(10), 386-422.

Brewton, J., \& Schiemann, W. A. (2003). Measurement: the missing ingredient in today's CRM strategies. Journal of cost management, 17(1), 5-14.

Chang, W., Park, J. E., \& Chaiy, S. (2010). How does CRM technology transform into organizational performance? A mediating role of marketing capability. Journal of Business Research, 63(8), 849-855.

Chatfield, A. T., \& Reddick, C. G. (2018). Customer agility and responsiveness through big data analytics for public value creation: A case study of Houston 311 on-demand services. Government Information Quarterly, 35(2), 336-347.

Chen, H., Cohen, P., \& Chen, S. (2010). How big is a big odds ratio? Interpreting the magnitudes of odds ratios in epidemiological studies. Communications in Statistics: Simulation and Computation, 39(4), 860-864.

Christopher, M. (2000). The agile supply chain: competing in volatile markets. Industrial marketing management, 29(1), 37-44.

Dove, R. (2001). Response Ability: The Language, Structure, and Culture of the Agile Enterprise. New York: Wiley Publications

Dubey, R., \& Gunasekaran, A. (2015). Agile manufacturing: framework and its empirical validation. The International Journal of Advanced Manufacturing Technology, 76, 21472157.

Dyche, J. (2002). The CRM handbook: A business guide to customer relationship management. USA: Addison-Wesley Professional.

Edinger, S. (2018, December 20). Why CRM projects fail and how to make them more successful. Harvard Business Review. Retrieved from https://hbr.org/2018/12/why-crm-projects-failand-how-to-make-them-more-successful

Elmuti, D., Jia, H., \& Gray, D. (2009). Customer relationship management strategic application and organizational effectiveness: an empirical investigation. Journal of Strategic marketing, 17(1), 75-96.

Englund, H., \& Gerdin, J. (2015). Developing enabling performance measurement systems: on the interplay between numbers and operational knowledge. European Accounting Review, 24(2), 277-303. 
Ernst, H., Hoyer, W. D., Krafft, M., \& Krieger, K. (2011). Customer relationship management and company performance - the mediating role of new product performance. Journal of the academy of marketing science, 39(2), 290-306.

Feinberg, R., \& Kadam, R. (2002). E-CRM Web service attributes as determinants of customer satisfaction with retail Web sites. International Journal of Service Industry Management, 13(5), 432-451.

Feiler, P., \& Teece, D. (2014). Case study, dynamic capabilities and upstream strategy: Supermajor EXP. Energy Strategy Reviews, 3, 14-20.

Fliedner, G., \& Vokurka, R. J. (1997). Agility: competitive weapon of the 1990s and beyond?. Production and Inventory Management Journal, 38(3), 19-24.

Fornell, C., \& Larcker, D. (1981). Structural Equation Models with Unobservable Variables and Measurement Error: Algebra and Statistics. Journal of Marketing Research, 18(3), 382388.

Garrido-Moreno, A., Lockett, N., \& García-Morales, V. (2014). Paving the way for CRM success: The mediating role of knowledge management and organizational commitment. Information \& Management, 51(8), 1031-1042.

Garrido-Moreno, A., \& Padilla-Meléndez, A. (2011). Analyzing the impact of knowledge management on CRM success: The mediating effects of organizational factors. International Journal of Information Management, 31(5), 437-444.

Gunasekaran, A. (1998). Agile manufacturing: enablers and an implementation framework. International journal of production research, 36(5), 1223-1247.

Haislip, J. Z., \& Richardson, V. J. (2017). The effect of Customer Relationship Management systems on firm performance. International Journal Accounting Inf. Systems, 27, 16-29.

Harrigan, P., Ramsey, E., \& Ibbotson, P. (2011). Critical factors underpinning the e-CRM activities of SMEs. Journal of Marketing Management, 27(5-6), 503-529.

Homburg, C., Grozdanovic, M., \& Klarmann, M. (2007). Responsiveness to customers and competitors: the role of affective and cognitive organizational systems. Journal of Marketing, 71(3), 18-38.

Hunt, S. D. (2000). Synthesising Resource-based, Evolutionary and Neoclassical Thought. London: Routledge.

Hunt, S. D. (2001). Commentary-A General Theory of Competition: issues, answers and an invitation. European Journal of Marketing, 35(6), 524-548.

Hunt, S. D. (2012). The evolution of resource-advantage theory: Six events, six realizations, six contributions. Journal of Historical Research in Marketing, 4(1), 7-29.

Hunt, S. D., \& Arnett, D. B. (2004). Market segmentation strategy, competitive advantage, and public policy: Grounding segmentation strategy in resource-advantage theory. Australasian Marketing Journal, 12(1), 7-25.

Hunt, S. D., \& Davis, D. F. (2008). Grounding supply chain management in resource-advantage theory. Journal of supply chain management, 44(1), 10-21

Hunt, S. D., \& Lambe, C. J. (2000). Marketing's contribution to business strategy: market orientation, relationship marketing and resource-advantage theory. International Journal of Management Reviews, 2(1), 17-43.

Hunt, S. D., \& Madhavaram, S. (2006). Teaching marketing strategy: Using resource-advantage theory as an integrative theoretical foundation. Journal of Marketing Education, 28(2), 93-105.

Hunt, S. D., \& Morgan, R. M. (1995). The comparative advantage theory of competition. Journal of marketing, 59(2), 1-15. 
Hunt, S. D., \& Morgan, R. M. (1997). Resource-advantage theory: a snake swallowing its tail or a general theory of competition?. Journal of Marketing, 61(4), 74-82.

Jain, R., Jain, S., \& Dhar, U. (2002). Measuring customer relationship management. Journal of Services Research, 2(2), 97-109.

Jordan, S., \& Messner, M. (2012). Enabling control and the problem of incomplete performance indicators. Accounting Organizations and Society, 37(8), 544-564.

Kim, H. S., \& Kim, Y. G. (2009). A CRM performance measurement framework: Its development process and application. Industrial marketing management, 38(4), 477-489.

Kim, J., Suh, E., \& Hwang, H. (2003). A model for evaluating the effectiveness of CRM using the balanced scorecard. Journal of interactive Marketing, 17(2), 5-19.

Kumar, V. (2008). Managing Customers for Profit. Wharton School Publishing, Upper Saddle River, NJ.

Lindgreen, A., Palmer, R., Vanhamme, J., \& Wouters, J. (2006). A relationship-management assessment tool: Questioning, identifying, and prioritizing critical aspects of customer relationships. Industrial Marketing Management, 35(1), 57-71.

Lisi, I. E. (2015). Translating environmental motivations into performance: The role of environmental performance measurement systems. Management Accounting Research, 29, 27-44.

Lu, Y., \& Ramamurthy. K. (Ram), (2011). Understanding the Link Between Information Technology Capability and Organizational Agility: An Empirical Examination. MIS Quarterly, 35(4), 931-954.

Micheli, P., \& Mura, M. (2017). Executing strategy through comprehensive performance measurement systems. International Journal of Operations \& Production Management, 37(4), 423-443.

Minami, C., \& Dawson, J. (2008). The CRM process in retail and service sector firms in Japan: Loyalty development and financial return. Journal of Retailing and Consumer Services, 15(5), 375-385.

Payne, A., \& Frow, P. (2005). A strategic framework for customer relationship management. Journal of marketing, 69(4), 167-176.

Podsakoff, P. M., MacKenzie, S. B., Lee, J. Y., \& Podsakoff, N. P. (2003). Common method biases in behavioral research: A critical review of the literature and recommended remedies. Journal of applied psychology, 88(5), 879.

Reimann, M., Schilke, O., \& Thomas, J. S. (2010). Customer relationship management and firm performance: the mediating role of business strategy. Journal of the academy of marketing science, 38(3), 326-346.

Reinartz, W., Krafft, M., \& Hoyer, W. D. (2004). The customer relationship management process: Its measurement and impact on performance. Journal of marketing research, 41(3), 293305.

Roberts, N., \& Grover, V. (2012a). Investigating firm's customer agility and firm performance: The importance of aligning sense and respond capabilities. Journal of Business Research, 65(5), 579-585.

Roberts, N., \& Grover, V. (2012b). Leveraging information technology infrastructure to facilitate a firm's customer agility and competitive activity: An empirical investigation. Journal of Management Information Systems, 28(4), 231-270.

Ryals, L. (2005). Making customer relationship management work: the measurement and profitable management of customer relationships. Journal of marketing, 69(4), 252-261. 
Sharifi, H., \& Zhang, Z. (1999). A methodology for achieving agility in manufacturing organisations: An introduction. International journal of production economics, 62(1-2), $7-22$.

Sivaraks, P., Krairit, D., \& Tang, J. C. (2011). Effects of e-CRM on customer-bank relationship quality and outcomes: The case of Thailand. The Journal of High Technology Management Research, 22(2), 141-157.

Swafford, P. M., Ghosh, S., \& Murthy, N. (2008). Achieving supply chain agility through IT integration and flexibility. International Journal of Production Economics, 116(2), 288297.

Tallon, P. P., \& Pinsonneault, A. (2011). Competing perspectives on the link between strategic information technology alignment and organizational agility: insights from a mediation model. Mis Quarterly, 35(2), 463-486.

Weill, P., Subramani, M., \& Broadbent, M. (2002). Building IT infrastructure for strategic agility. MIT Sloan Management Review, 44(1), 57-65.

Wooliscroft, B., \& Hunt, S. D. (2012). The evolution of resource-advantage theory. Journal of Historical Research in Marketing, 4(1), 7-29.

World Travel \& Tourism Council (WTTC) (2017). Economic Impact Reports. Retrieved from: https://www.wttc.org/-/media/files/reports/economic-impact-research/regions2017/world2017.pdf

World Travel \& Tourism Council (WTTC) (2018). Economic Impact Reports. Retrieved from https://www.wttc.org/economic-impact/country-analysis/country-reports/

Wouters, M., \& Wilderom, C. (2008). Developing performance measurement systems as enabling formalization: A longitudinal field study of a logistics department. Accounting Organizations and Society, 33(4-5), 488-516.

Yang, C., \& Liu, H. M. (2012). Boosting firm performance via enterprise agility and network structure. Management Decision, 50(6), 1022-1044.

Yusuf, Y. Y., Gunasekaran, A., Adeleye, E. O., \& Sivayoganathan, K. (2004). Agile supply chain capabilities: Determinants of competitive objectives. European Journal of Operational Research, 159(2), 379-392.

Yusuf, Y. Y., Sarhadi, M., \& Gunasekaran, A. (1999). Agile manufacturing: The drivers, concepts and attributes. International Journal of production economics, 62(1-2), 33-43.

Zablah, A. R., Bellenger, D. N., \& Johnston, W. J. (2004). An evaluation of divergent perspectives on customer relationship management: Towards a common understanding of an emerging phenomenon. Industrial marketing management, 33(6), 475-489.

Zineldin, M. (2005). Quality and customer relationship management (CRM) as competitive strategy in the Swedish banking industry. The TQM magazine, 17(4), 329-344. 